\title{
Analisis Kelayakan Finansial Pembangunan Gedung Parkir Sukaramai Trade Center II
}

\author{
Financial Feasibility Analysis of Sukaramai Trade Center II Parking Building
}

\author{
Nelson Yuli Chandra ${ }^{1}$, Hendra Taufik ${ }^{1, *}$, Mardani Sebayang1 \\ ${ }^{1}$ Teknik Sipil, Universitas Riau, Jl. HR Soebrantas KM. 12,5, Pekanbaru, Indonesia
}

\author{
* Penulis korespondensi : taufik2701@gmail.com \\ Tel.: +62-813-1976-9489; fax :- \\ Diterima: 21 Oktober 2020; Direvisi: 28 April 2021; Disetujui: 29 April 2021 \\ DOI: 10.25299/saintis.2021.vol21(01).5718
}

\begin{abstract}
Abstrak
Pembangunan gedung parkir Sukaramai Trade Center II ini direncanakan pada tahun 2016 dan di kelola oleh pihak PT. Makmur Papan Permata sebagai penunjang bangunan Sukaramai Trade Center I untuk memenuhi lahan parkir kedepannya, dikarenakan adanya pembangunan tambahan Sukaramai Trade Center III sehingga pembangunan gedung parkir Sukaramai Trade Center II harus dilaksanakan, sesuai dengan bertambahnya permintaan konsumen serta lahan yang tidak memenuhi. Tujuan dari penelitian ini adalah untuk mengetahui apakah pembangunan dari gedung parkir Sukaramai Trade Center II layak untuk dilaksanakan berdasarkan aspek analisis kelayakan finansial dan untuk mengetahui faktor-faktor yang perlu diperhatikan seperti metode tarif parkir yang digunakan. Metode penelitian ini menggunakan observasi dan wawancara. Berdasarkan data dan hasil penelitian di ketahui luas bangunan 3.466 m2, kapasitas parkir sepeda motor 1103 kendaraan, parkir mobil 325 kendaraan, rata-rata 5 tahun belakang tingkat pertumbuhan kendaraan 10,48\%, inflasi 4,87\%, menggunakan suku bunga tertinggi pada bank BUMN yaitu bank BTN sebesar 10,50\%, sehingga memerlukan total biaya Rp 42.472.500.000,- umur ekonomis bangunan 50 tahun. Dengan tarif parkir/jam Rp 2000,- untuk kendaraan sepeda motor, Rp 5000,- untuk kendaraan mobil, ditinjau dari aspek analisis kelayakan finansial dengan umur bangunan 50 tahun : Net Present Value $(\mathrm{NPV})=$ Rp. $(-12.333 .948 .000$,$) Benefit Cost Ratio(BCR )=0,504$, Internal Rate of Return(IRR)=6,69\%, dinyatakan tidak layak untuk dilaksanakan. Pembangunan gedung parkir tersebut perlu memperhatikan tingkat pertumbuhan kendaraan, kapasitas parkir, tingkat inflasi dan tingkat suku bunga, serta tarif parkir yang ditetapkan oleh Pemerintah.
\end{abstract}

Kata Kunci: Analisis Finansial, inflasi dan karakteristik parkir

\section{Abstract}

The construction of the Sukaramai Trade Center II parking building was planned in 2016 and managed by PT. Makmur Papan Permata is supporting the Sukaramai Trade Center I building to fill the parking lot in the future, due to the additional construction of the Sukaramai Trade Center III so that the construction of the Sukaramai Trade Center II parking building must be carried out, by increasing consumer demand and land that does not meet. The purpose of this study is to determine whether the construction of the Sukaramai Trade Center II parking building is feasible to carry out based on the aspect of financial feasibility analysis and to determine the factors that need to be considered such as the parking fee method used. This research method uses observation and interviews. Based on data and research results, it is known that the building area is 3,465.98 m2, the parking capacity for motorbikes is 1103 vehicles, 325 car parks, the average 5 years behind the vehicle growth rate is $10.48 \%$, inflation is $4.87 \%$, using the highest interest rate in state-owned banks, namely BTN banks at $10.50 \%$ so that it requires a total cost of IDR 42,472,500,000, - the economic age of the building is 50 years. With parking rates/hour Rp. 2000, - for motorbikes, Rp. 5000, - for cars, in terms of financial feasibility analysis aspects with a building age of 50 years: Net Present Value $(N P V)=R p .(-12,333,948,000$,$) Benefit-Cost Ratio (B C R)=0.504$, Internal Rate of Return (IRR) $=6.69 \%$, declared unfit to be implemented . The construction of the parking building need to pay attention to the growth rate of vehicles, parking capacity, inflation rates, and interest rates, as well as parking rates set by the Government.

Keywords: Analysis Financial, Inflation, and parking characteristics

\section{PENDAHULUAN}

Pembangunan Sukaramai Trade Center terbagi atas tiga bangunan yang berbeda. Pertama adalah Sukaramai Trade Center I, bangunan ini merupakan bangunan lama yang pernah mengalami kebakaran dan sampai sekarang bangunan ini masih dalam renovasi, akan tetapi sebagian bangunan ini masih dipergunakan. Kedua adalah Sukaramai Trade Center II, bangunan ini adalah bangunan yang sedang dalam pembangunan saat ini dan memiliki tujuh lantai, lima lantai digunakan untuk parkir dan dua lantai digunakan untuk pertokoan. Ketiga adalah Sukaramai Trade Center III, bangunan ini masih dalam perencanaan dan akan dibangun setelah Sukaramai Trade Center II selesai.

Pembangunan gedung parkir Sukaramai Trade Center II berfungsi sebagai penunjang bangunan sukaramai trade center I dan rencana pembangunan Sukaramai Trade Center III. Ketiga bangunan Trade Center ini dibangun pada lahan yang terbatas di area pertengahan kota, akibatnya gedung parkir Trade Center II menjadi solusi yang 
terbaik dalam memenuhi ketersediaan parkir bangunan-bangunan tersebut.

Lokasi pasar Sukaramai ini berada di pemukiman padat penduduk sehingga kurangnya lahan yang bisa dipergunakan sebagai lahan parkir dan pasar ini terletak di pinggir Jalan arteri dengan kondisi lalu lintas yang padat dan sering terjadi kemacetan karena banyak pengunjung pasar yang memarkirkan kendaraan mereka di badan jalan [1].

Pusat perbelanjaan di Sukaramai Trade Center ini lokasinya selalu macet karena berada di tengah pasar dan juga pusat pertokoan textile serta pertokoan barang-barang harian lainnya. Proyek Sukaramai Trade Center II (STC II) merupakan proyek pembangunan gedung parkir yang dibangun secara vertikal dan bertujuan untuk menyediakan lahan parkir untuk bangunan Sukaramai Trade Center I (STC I) dan juga untuk bangunan Sukaramai Trade Center III (STC III)

Adapun tujuan dilakukan penelitian pada gedung parkir bertingkat Sukaramai Trade Center II ini adalah menganalisis kelayakan finansial gedung parkir bertingkat Sukaramai Trade Center II dan menganalisis pengaruh metode tarif parkir yang digunakan pada gedung parkir bertingkat Sukaramai Trade Center II.

\section{Karakteristik Parkir}

Karakteristik parkir sebagai dasar atau utama dalam penilaian kepada pelayanan parkir dan permasalahan parkir yang terjadi pada lokasi parkir. [2]Adapun arakteristik parkir dapat diketahui dengan kondisi perparkiran yang terjadi dilokasi parkir seperti volume parkir, lama waktu parkir dan kapasitas parkir[3].

\section{Volume Parkir}

Volume parkir merupakan kondisi jumlah kendaraan yang parkir pada periode waktu tertentu. Waktu yang di pakai dalam keadaan parkir kendaraan, dinyatakan dalam menit atau jam, yang disebut lama parkir. Penggunaan ruang parkir dapat diketahui dengan jumlah data penggunaan parkir[2].

\section{Lama Waktu Parkir}

Lama Waktu Parkir merupakan waktu yang digunakan oleh kendaraan selama berada pada ruang parkir. Lama waktu parkir biasanya dinyatakan dalam satuan jam. Suatu ruang parkir akan mampu melayani lebih banyak kendaraan jika digunakan untuk parkir kendaraan dalam waktu yang singkat dibandingkan dengan ruang parkir yang dihabiskan dalam waktu yang lama. Waktu parkir juga merupakan suatu tinjauan yang sangat diperhatikan karena dalam waktu parkir pihak mengelola bisa mendapatkan keuntungan dengan menggunakan beberapa metode standar harga tarif parkir[4].

\section{Kapasitas Parkir}

Kapasitas ruang parkir adalah jumlah ruang parkir dalam menampung kendaraan yang sedang parkir. Kendaraan pemakai ruang parkir ini ditinjau dari kendaraan yang datang untuk parkir, dan pergi meninggalkan ruang parkir atau meninggalkan lahan parkir[5]. Tinjauan dari kejadian akan memberikan dampak besaran maupun nilai pada kapasitas dari ruang parkir.

\section{Gedung Parkir}

Gedung parkir merupakan suatu bangunan yang di buat khusus untuk menjadi lahan parkir kendaraan [3]. Gedung parkir biasanya dibangun pada daerah perkotaan yang tidak mempunyai lahan parkir yang memadai [6]. Gedung parkir juga bisa dikombinasikan dengan pusat perbelanjaan.

\section{Pendapatan Parkir}

Pendapatan parkir biasanya tergantung dari penetapan harga jasa parkir yang digunakan. Penetapan harga jasa parkir mengikuti aturan biaya parkir yang ditetapkan pemerintah dan bisa berdasarkan fasilitas parkir. Dalam menentukan harga parkir kita bisa berpedoman kepada hukum penawaran dan permintaan. Semakin murah harga jasa fasilitas parkir maka permintaan parkir semakin besar sedangkan semakin besar penawaran semakin besar fasilitas parkir yang disediakan, maka semakin murah harga jasa fasilitas parkir[7]. Secara umum sistem penetapan tarif parkir adalah sebagai berikut:

1. Sistem tetap (flat), sistem pembayaran besaran tarif yang tidak membedakan lama waktu parkir suatu kendaraan.

2. Sistem berubah sesuai waktu (progresif), sistem pembayaran besaran tarif yang memperhatikan lama waktu parkir suatu kendaraan.

3. Sistem kombinasi, sistem pembayaran besaran tarif yang mengkombinasikan antara sistem flat dan progresif.

\section{Perkiraan Biaya Pembangunan}

Biaya pembangunan yang direncanakan untuk membangun sebuah gedung terdiri dari perkiraan biaya investasi biaya pengelolaan yang terdiri dari biaya operasional, inventaris dan eksternal

\section{Analisis Kelayakan Finansial}

Analisis kelayakan finansial pada umumnya digunakan untuk mencari tingkat kelayakan suatu proyek. Dalam melakukan analisis kelayakan finansial proyek biasanya di lihat pada lembaga atau investor maupun owner yang menanamkan model langsung dalam suatu proyek [8]. Tujuan dalam menganalisis finansial adalah mengetahui 
tingkat kelayakan pembangunan suatu konstruksi maka semua perkiraan biaya diperhitungkan [9]. Analisis kelayakan finansial pada umumnya digunakan dalam mencari keuntungan maupun kerugian yang menyeluruh pada suatu pembangunan.

Metode yang digunakan adalah :

\section{Metode Net Present Value (NPV)}

Metode ini membandingkan antara semua komponen biaya pengeluaran dan nilai manfaat dari suatu proyek. Sehingga NPV diartikan sebagai selisih antara Present Value dari nilai manfaat dan Present Value dari nilai biaya (cost) [10].

NPV > 0 pembangunan bisa dilaksanakan / layak.

NPV $<0$ pembangunan tidak bisa dilaksanakan / tidak layak.

2. Metode Benefit Cost Ratio (BCR)

Metode ini digunakan untuk mencari nilai indeks yang menggambarkan pemanfaatan biaya yang di terima.

BCR $>1$ Artinya pembangunan layak

$\mathrm{BCR}<1$ Artinya pembangunan tidak layak

3. Internal Rate of Return (IRR)

Internal Rate of Return merupakan suatu nilai yang menunjukkan harga discount rate pada saat nilai NPV $=0$ [11].

IRR $\geq$ Suku bunga, pembangunan bisa dilaksanakan layak.

IRR < Suku bunga, pembangunan tidak bisa dilaksanakan atau tidak layak.

\section{METODOLOGI}

Penelitian berada di Jl. Jenderal Sudirman, Kecamatan Pekanbaru Kota, Riau. Lahan di sekitar lokasi bangunan yang sangat sempit membuat bangunan Sukaramai Trade center II ini bisa digunakan sebagai alternatif oleh pemilik kendaraan beroda empat untuk memarkirkan kendaraannya di Sukaramai Trade center II yang berbelanja di toko-toko di sekitarnya. Lokasi penelitian dapat dilihat pada Gambar 1.

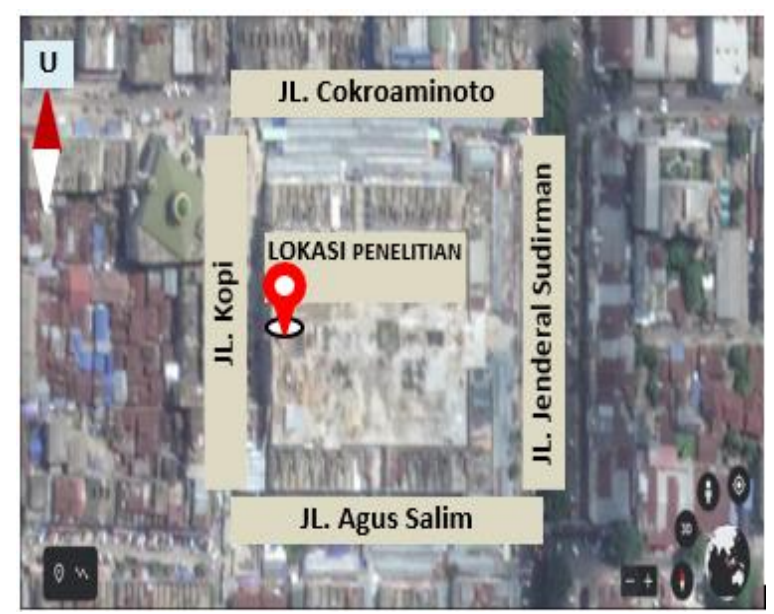

Gambar 1. Lokasi Pembangunan Gedung Parkir (STC II) (Earth, 2018)
Data yang diperlukan pada penelitian analisis kelayakan finansial Sukaramai Trade Center II ini antara lain adalah:

1. Data sekunder dari pihak proyek As Built Drawing tentang desain gedung parkir dan biaya pembangunan.

2. Data primer yakni data survei yang dilakukan di sekitar lokasi pembangunan gedung Sukaramai Trade Center II melalui wawancara dan mengisi kuesioner kepada pengunjung.

3. Data tarif parkir yang direncanakan berdasarkan peraturan pemerintah daerah menggunakan metode flat, progresif dan kombinasi.

Data yang diperlukan maupun dibutuhkan adalah data primer dan sekunder. Data primer merupakan data yang di ambil secara langsung dilapangan, sedangkan data sekunder merupakan data yang diambil dari data yang sudah ada dan tersusun melalui pihak lain seperti lembaga instansi tempat penelitian [12].

1. Data Primer

Data primer yang dipergunakan adalah data jam puncak parkir yang dilakukan dengan cara survei menggunakan kuesioner kepada pengunjung yang dilakukan pada hari normal tiga kali yakni hari senin, selasa, kamis dan juga pada hari libur hari sabtu dan minggu pada jam 09.00, 13.00 dan 16.00 WIB.

\section{Data Sekunder}

Data sekunder diperoleh dari pihak owner dan pihak kontraktor yang membangun gedung parkir Sukaramai Trade Center II [13].

Penelitian dilakukan menggunakan teknik sampel yakni non probability sample dengan teknik purposive sampel. Teknik purposive sampel merupakan teknik pengambilan sampel dari sumber data dengan beberapa pertimbangan[2]. Penelitian ini dimulai dengan studi pustaka yang berkaitan dengan analisis kelayakan finansial. Setelah itu dilakukan pengumpulan data primer dengan metode wawancara pada pengunjung disekitar lokasi penelitian dan data sekunder yang didapat langsung dari pihak owner maupun kontraktor. Hasil pengumpulan data ini dilakukan analisis untuk mencari tarif parkir menggunakan metode flat, progresif dan kombinasi. Setelah didapatkan nilai tarif parkir, dapat dihitung pendapatan parkir sehingga dilanjutkan dengan menganalisis kelayakan finansial menggunakan metode NPV, BCR dan IRR. Dari hasil analisis finansial ini, dapat disimpulkan layak atau tidaknya bangunan tersebut. Jika bangunan dikatakan layak secara finansial maka dilanjutkan dengan metode payback period dan analisis sensitivitas, sedangkan jika bangunan dikatakan tidak layak secara finansial maka langsung pada pembahasan dan kesimpulan. 


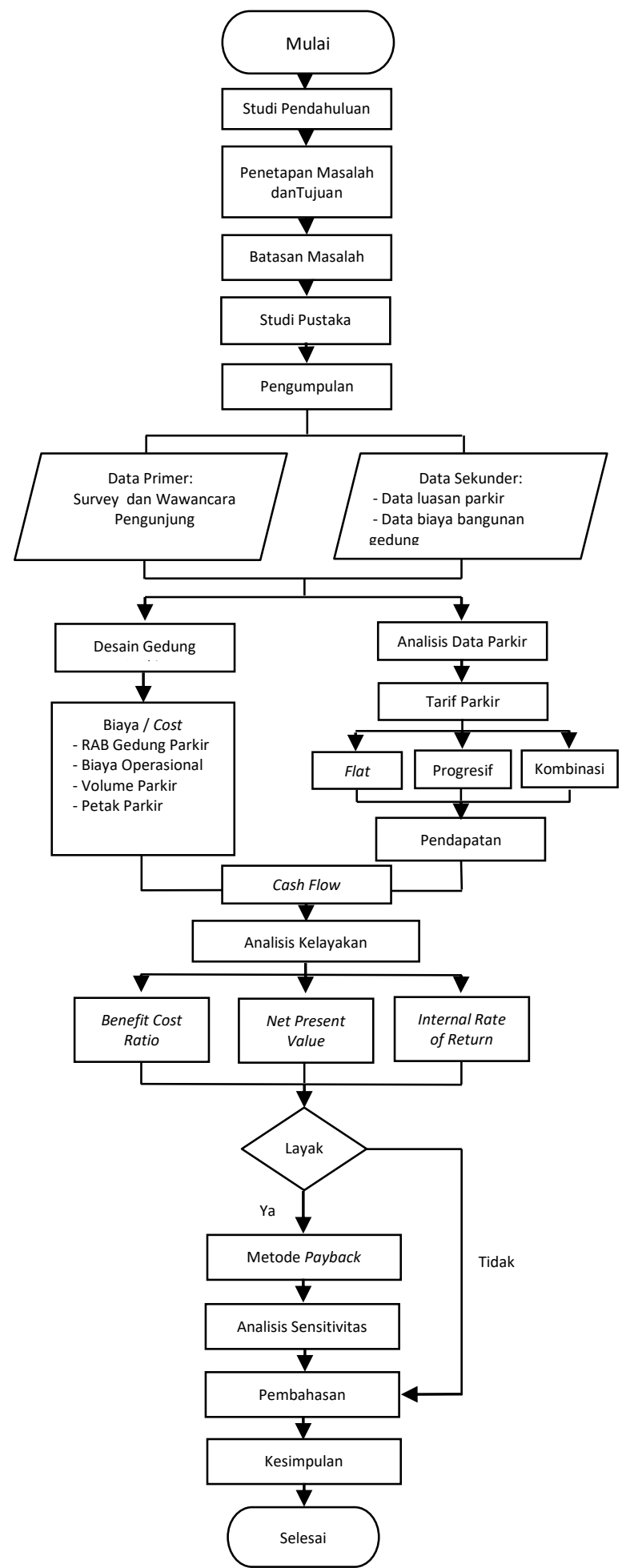

Gambar 2. Bagan Alir Penelitian

Dari Gambar 2 dapat disimpulkan bahwa nilai Net Present Value, Benefit Cost Ratio dan Internal Rate of Return memenuhi ketentuan maka penelitian dilanjutkan dengan metode Payback Period dan metode Analisis Sensitivitas, Jika nilai
NPV, BCR dan IRR tidak memenuhi ketentuan, maka penelitian dilanjutkan dengan kesimpulan dan selesai.

\section{HASIL DAN DISKUSI}

Pembangunan Gedung Sukaramai Trade Center II terletak di Jalan Jenderal Sudirman, Kecamatan Pekanbaru Kota, Riau. Sukaramai Trade Center tediri dari tiga bangunan, yang pertama Trade Center I adalah pusat perbelanjaan, yang kedua Trade Center II adalah gedung parkir, yang ketiga Trade Center III Dalam Proses rencana pembangunan Hotel. Proyek pembangunan ini dilaksanakan oleh kontraktor PT. Trimatra Liguna. Luas lahan Sukaramai Trade Center keseluruhan 28.432,38 $\mathrm{m}^{2}$, luas bangunan Sukaramai Trade Center I 12.773,69 $\mathrm{m}^{2}$ dan luas bangunan Sukaramai Trade Center II 3.465,98 $\mathrm{m}^{2}$.

Fasilitas parkir yang digunakan pada gedung parkir Sukaramai Trade Center II, yaitu dalam bentuk pola parkir kendaraan dua sisi pada parkir sepeda motor dengan sudut parkir $90^{\circ}$ dan ukuran petak parkir 1 x 2 meter. Pada parkir kendaraan beroda empat digunakan satu sisi dengan sudut parkir $90^{\circ}$ sehingga untuk ukuran petak parkir $3 \times 5$ meter. Secara detail dapat dilihat jumlah petak, sudut petak dan ukuran petak pada Tabel 1 .

Tabel 1. Karakteristik Parkir STC II

\begin{tabular}{cccccc}
\hline & & \multicolumn{2}{c}{$\begin{array}{c}\text { Jumlah } \\
\text { No. }\end{array}$} & Lantai & \multicolumn{2}{c}{$\begin{array}{c}\text { Sudut } \\
\text { Kendaraandaraan ( }\end{array}$} \\
\cline { 3 - 6 } & & Motor & Mobil & Motor & Mobil \\
\hline 1 & LG & 66 & - & 90 & 90 \\
2 & GF & 67 & - & 90 & 90 \\
3 & I & - & 67 & 90 & 90 \\
4 & II & - & 64 & 90 & 90 \\
5 & III & - & 72 & 90 & 90 \\
6 & IV & - & 67 & 90 & 90 \\
7 & V & - & 55 & 90 & 90 \\
8 & B1 & 970 & - & 90 & 90 \\
\hline \multicolumn{7}{r}{ Total } & 1103 & 325 & & \\
\hline
\end{tabular}

Sumber : (Trimatra Liguna, 2020)

Volume parkir kendaraan untuk gedung parkir Sukaramai Trade Center II didapatkan dari jumlah volume parkir kendaraan sementara yang akan dipindahkan ke gedung parkir Sukaramai Trade Center II. Dari data volume parkir didapatkan jumlah volume parkir untuk kendaraan sepeda motor dengan nilai 470 kendaraan/hari, sedangkan untuk kendaraan mobil didapatkan nilai sebesar 198 kendaraan/hari, secara lengkap dapat dilihat pada Tabel 2 dan Tabel 3. 
Tabel 2. Volume Parkir Sepeda Motor Sukaramai Trade Center

\begin{tabular}{cccc}
\hline No & Waktu (WIB) & $\begin{array}{c}\text { Volume } \\
\text { (Sepeda } \\
\text { Motor) }\end{array}$ & Satuan \\
\hline 1 & $09.00-11.00$ & 80 & Kendaraan \\
2 & $11.00-13.00$ & 108 & Kendaraan \\
3 & $13.00-15.00$ & 152 & Kendaraan \\
4 & $15.00-17.00$ & 94 & Kendaraan \\
5 & $17.00-19.00$ & 36 & Kendaraan \\
\hline & Jumlah & 470 & Kendaraan \\
\hline
\end{tabular}

Tabel 3. Volume Parkir Mobil Sukaramai Trade Center

\begin{tabular}{cccc}
\hline No & Waktu (WIB) & $\begin{array}{c}\text { Volume } \\
\text { (Mobil) }\end{array}$ & Satuan \\
\hline 1 & $09.00-11.00$ & 57 & Kendaraan \\
2 & $11.00-13.00$ & 69 & Kendaraan \\
3 & $13.00-15.00$ & 45 & Kendaraan \\
4 & $15.00-17.00$ & 23 & Kendaraan \\
5 & $17.00-19.00$ & 4 & Kendaraan \\
\hline & Jumlah & 198 & Kendaraan \\
\hline
\end{tabular}

Pada penelitian ini diketahui waktu rata-rata lama parkir kendaraan sepeda motor terdapat pada jam 13.00-15.00 WIB dengan nilai 3,234 jam/kendaraan sedangkan untuk kendaraan mobil didapatkan pada jam 11.00-13.00 dengan waktu 3,485 secara lengkap dapat dilihat pada Tabel 4 untuk kendaraan sepeda motor dan Tabel 5 untuk kendaraan mobil.

Tabel 4. Volume Parkir Sepeda Motor Sukaramai Trade Center

\begin{tabular}{ccc}
\hline No & Waktu (WIB) & $\begin{array}{c}\text { Rata - rata Lama } \\
\text { Parkir (jam/kend) }\end{array}$ \\
\hline 1 & $09.00-11.00$ & 1,702 \\
2 & $11.00-13.00$ & 2,298 \\
3 & $13.00-15.00$ & 3,234 \\
4 & $15.00-17.00$ & 2,000 \\
5 & $17.00-19.00$ & 0,766 \\
\hline
\end{tabular}

Tabel 5. Volume Parkir Mobil Sukaramai Trade

\begin{tabular}{ccc}
\hline Center & \\
\hline No & Waktu (WIB) & $\begin{array}{c}\text { Rata - rata Lama } \\
\text { Parkir (jam/kend) }\end{array}$ \\
\hline 1 & $09.00-11.00$ & 2,879 \\
2 & $11.00-13.00$ & 3,485 \\
3 & $13.00-15.00$ & 2,273 \\
4 & $15.00-17.00$ & 1,162 \\
5 & $17.00-19.00$ & 0,202 \\
\hline
\end{tabular}

Hasil wawancara dan analisa data didapatkan kapasitas parkir untuk kendaraan sepeda motor terbanyak pada waktu 17.00-19.00 WIB dengan nilai 1440 kendaraan/jam, kapasitas parkir paling sedikit terdapat pada waktu 13.0015.00 WIB dengan nilai 341 kendaraan/jam sedangkan kapasitas parkir untuk kendaraan mobil terbanyak pada waktu 17.00-19.00 WIB dengan nilai 1609 kendaraan/jam, kapasitas parkir paling sedikit terdapat pada waktu 11.00-13.00 WIB dengan nilai 93 kendaraan/jam, secara lengkap dapat dilihat pada Tabel 6 dan Tabel 7 .

Tabel 6. Kapasitas Parkir Kendaraan Sepeda Motor

\begin{tabular}{|c|c|c|c|c|}
\hline No & $\begin{array}{l}\text { Waktu } \\
\text { (WIB) }\end{array}$ & $\begin{array}{l}\text { Lama Rata - } \\
\text { rata Parkir } \\
\text { (jam/kend) }\end{array}$ & $\begin{array}{c}\text { Jumlah } \\
\text { Petak } \\
\text { Parkir } \\
\text { (Petak) }\end{array}$ & $\begin{array}{c}\text { Kapasitas } \\
\text { (Kendaraan } \\
\text { /Jam) }\end{array}$ \\
\hline 1 & $\begin{array}{c}09.00- \\
11.00\end{array}$ & 1,702 & 1103 & 648 \\
\hline 2 & $\begin{array}{c}11.00- \\
13.00\end{array}$ & 2,298 & 1103 & 480 \\
\hline 3 & $\begin{array}{c}13.00- \\
15.00\end{array}$ & 3,234 & 1103 & 341 \\
\hline 4 & $\begin{array}{c}15.00- \\
17.00\end{array}$ & 2,000 & 1103 & 552 \\
\hline 5 & $\begin{array}{c}17.00- \\
19.00\end{array}$ & 0,766 & 1103 & 1440 \\
\hline
\end{tabular}

Tabel 7. Kapasitas Parkir Kendaraan Mobil

\begin{tabular}{|c|c|c|c|c|}
\hline No & $\begin{array}{l}\text { Waktu } \\
\text { (WIB) }\end{array}$ & $\begin{array}{l}\text { Lama Rata - } \\
\text { rata Parkir } \\
\text { (jam/kend) }\end{array}$ & $\begin{array}{c}\text { Jumlah } \\
\text { Petak } \\
\text { Parkir } \\
\text { (Petak) }\end{array}$ & $\begin{array}{l}\text { Kapasitas } \\
\text { Kendaraan } \\
\text { /Jam) }\end{array}$ \\
\hline 1 & $\begin{array}{c}09.00- \\
11.00\end{array}$ & 2,879 & 325 & 113 \\
\hline 2 & $\begin{array}{c}11.00- \\
13.00\end{array}$ & 3,485 & 325 & 93 \\
\hline 3 & $\begin{array}{c}13.00- \\
15.00\end{array}$ & 2,273 & 325 & 143 \\
\hline 4 & $\begin{array}{c}15.00- \\
17.00\end{array}$ & 1,162 & 325 & 280 \\
\hline 5 & $\begin{array}{c}17.00- \\
19.00\end{array}$ & 0,202 & 325 & 1609 \\
\hline
\end{tabular}

Waktu untuk kendaraan sepeda motor terbanyak pada waktu 17.00-19.00 WIB dengan nilai 2880 kendaraan/jam, kapasitas parkir per periode waktu paling sedikit terdapat pada waktu 13.00-15.00 WIB dengan nilai 682 kendaraan/jam, dengan total kapasitas per hari adalah 6921 kendaraan, dapat dilihat pada Tabel 8 di bawah.

Tabel 8. Kapasitas Parkir Kendaraan Sepeda Motor Per Periode Waktu

\begin{tabular}{ccc}
\hline No & Waktu (WIB) & $\begin{array}{c}\text { Kapasitas Kendaraan Per } \\
\text { Periode waktu (Kendaraan) }\end{array}$ \\
\hline 1 & $09.00-11.00$ & 1296 \\
2 & $11.00-13.00$ & 960 \\
3 & $13.00-15.00$ & 682 \\
4 & $15.00-17.00$ & 1103 \\
5 & $17.00-19.00$ & 2880 \\
\hline \multicolumn{2}{l}{ Kapasitas Per Hari } & 6921 \\
\hline
\end{tabular}

Kendaraan mobil terbanyak pada waktu 17.00-19.00 WIB dengan nilai 3218 kendaraan/jam, kapasitas parkir per periode waktu paling sedikit terdapat pada waktu 11.00-13.00 WIB dengan nilai 187 kendaraan/jam, dengan total kapasitas per hari adalah 4475 kendaraan, dapat dilihat pada Tabel 9. 
Tabel 9. Kapasitas Parkir Kendaraan Mobil Per Periode Waktu

\begin{tabular}{ccc}
\hline No & Waktu (WIB) & $\begin{array}{c}\text { Kapasitas Kendaraan Per } \\
\text { Periode waktu (Kendaraan) }\end{array}$ \\
\hline 1 & $09.00-11.00$ & 226 \\
2 & $11.00-13.00$ & 187 \\
3 & $13.00-15.00$ & 286 \\
4 & $15.00-17.00$ & 560 \\
5 & $17.00-19.00$ & 3218 \\
\hline \multicolumn{2}{l}{ Kapasitas Per Hari } & 4475 \\
\hline
\end{tabular}

\section{Tingkat Pertumbuhan Kendaraan}

Dalam memperkirakan volume parkir, faktor yang mempengaruhi yakni faktor pertumbuhan kendaraan ringan dan inflasi sehingga dalam memprediksi pertumbuhan lalu-lintas berdasarkan data statistik. Dari data statistik pertumbuhan kendaraan ringan 5 tahun terakhir (Th 2015-2019) didapat tingkat pertumbuhan kendaraan ringan adalah $10,48 \%$ selengkapnya dapat dilihat pada Tabel 10 sedangkan untuk prediksi tarif parkir pada masa yang akan datang digunakan data inflasi. Dari data statistik inflasi 5 tahun terakhir ( Th 2015 - 2019) rata-rata inflasi sebesar 4,87\% dapat dilihat pada Tabel 11.

Tabel 10. Pertumbuhan Jumlah Kendaraan Kota Pekanbaru 2015 sampai 2019

\begin{tabular}{|c|c|c|c|c|c|}
\hline \multirow{2}{*}{ Uraian } & \multicolumn{5}{|c|}{ Tahun } \\
\hline & 2015 & 2016 & 2017 & 2018 & 2019 \\
\hline $\begin{array}{l}\text { Jumlah Kendaraan } \\
\text { Ringan (unit) }\end{array}$ & 93,7 & 36,8 & 46,9 & 49,2 & 50,5 \\
\hline Pertumbuhan (\%) & 21,5 & 7,0 & 8,3 & 8,0 & 7,6 \\
\hline $\begin{array}{l}\text { pertumbuhan Rata- } \\
\text { rata ( } \% \text { per Tahun) }\end{array}$ & & & 10,5 & & \\
\hline
\end{tabular}

Tabel 11. Tingkat Inflasi Kota Pekanbaru Tahun

\begin{tabular}{cccccc}
\multicolumn{7}{c}{$2015-2019$} & \multicolumn{5}{c}{ Inflasi } \\
Bulan & $\mathbf{2 0 1 5}$ & $\mathbf{2 0 1 6}$ & $\mathbf{2 0 1 7}$ & $\mathbf{2 0 1 8}$ & $\mathbf{2 0 1 9}$ \\
\hline Januari & 0,69 & 0,25 & 1,46 & 0,25 & $-0,1$ \\
Februari & 0,04 & $-0,5$ & 0,6 & $-0,5$ & $-0,32$ \\
Maret & 0,15 & 0,54 & 0,38 & 0,54 & 0,09 \\
April & $-0,05$ & $-1,26$ & 0,28 & $-1,26$ & 0,51 \\
Mei & 0,2 & 0,23 & 0,12 & 0,23 & 0,56 \\
Juni & 0,54 & 0,33 & 0,15 & 0,33 & 1,3 \\
Juli & 0,86 & 1,23 & 0,58 & 1,23 & 0,91 \\
Agustus & 1,04 & 0,13 & 0,2 & 0,13 & 0,36 \\
September & 0,43 & 0,94 & 0,3 & 0,94 & $-0,23$ \\
Oktober & 0,56 & 0,67 & 0,33 & 0,67 & $-0,04$ \\
November & 2,1 & 1,3 & 0,38 & 1,3 & $-0,26$ \\
Desember & 1,69 & 0,27 & 0,48 & 0,27 & $-0,22$ \\
Jumlah & 8,25 & 4,13 & 5,26 & 4,13 & 2,56 \\
\hline Rata-rata & & & & \\
Inflasi (\%per & & & & & \\
Tahun) & & & & &
\end{tabular}

\section{Prediksi Volume Parkir}

Dalam memprediksi volume parkir yang digunakan oleh gedung parkir Sukaramai Trade Center II sampai 50 tahun ke depan dengan tingkat pertumbuhan $10,48 \%$ per tahun dapat dilihat pada
Tabel 12 dan Tabel 13, jika prediksi volume parkir sudah melebihi atau melewati kapasitas parkir maka volume parkir pada tahun yang melewati tersebut dan seterusnya sama dengan volume kapasitas parkir, dikarenakan kapasitas lahan parkir yang tersedia tidak bisa menampung jumlah kendaraan yang melebihi kapasitas parker [14] .

Tabel 12. Prediksi Volume Sepeda Motor pada Sukaramai Trade Center

\begin{tabular}{ccc|ccc}
\hline No & Tahun & $\begin{array}{c}\text { Volume } \\
\text { Total } \\
\text { (Kend) }\end{array}$ & No & Tahun & $\begin{array}{c}\text { Volume } \\
\text { Total } \\
\text { (Kend) }\end{array}$ \\
\hline 1 & 2019 & 203 & 31 & 2049 & 3529 \\
2 & 2020 & 224 & 32 & 2050 & 3691 \\
3 & 2021 & 248 & 33 & 2051 & 3787 \\
4 & 2022 & 274 & 34 & 2052 & 3876 \\
5 & 2023 & 302 & 35 & 2053 & 3975 \\
\hline 6 & 2024 & 334 & 36 & 2054 & 4083 \\
7 & 2025 & 369 & 37 & 2055 & 4186 \\
8 & 2026 & 408 & 38 & 2056 & 4201 \\
9 & 2027 & 451 & 39 & 2057 & 4217 \\
10 & 2028 & 498 & 40 & 2058 & 4236 \\
\hline 11 & 2029 & 550 & 41 & 2059 & 4256 \\
12 & 2030 & 608 & 42 & 2060 & 4279 \\
13 & 2031 & 671 & 43 & 2061 & 4304 \\
14 & 2032 & 742 & 44 & 2062 & 4331 \\
15 & 2033 & 819 & 45 & 2063 & 4362 \\
\hline 16 & 2034 & 905 & 46 & 2064 & 4396 \\
17 & 2035 & 1000 & 47 & 2065 & 4433 \\
18 & 2036 & 1105 & 48 & 2066 & 4474 \\
19 & 2037 & 1220 & 49 & 2067 & 4519 \\
20 & 2038 & 1348 & 50 & 2068 & 4569 \\
\hline 21 & 2039 & 1490 & 51 & 2069 & 4625 \\
22 & 2040 & 1646 & 52 & 2070 & 4686 \\
23 & 2041 & 1818 & 53 & 2071 & 4753 \\
24 & 2042 & 2009 & 54 & 2072 & 4828 \\
25 & 2043 & 2219 & 55 & 2073 & 4910 \\
\hline 26 & 2044 & 2452 & 56 & 2074 & 5001 \\
27 & 2045 & 2670 & 57 & 2075 & 5102 \\
28 & 2046 & 2879 & 58 & 2076 & 5213 \\
29 & 2047 & 3109 & 59 & 2077 & 5336 \\
30 & 2048 & 3363 & 60 & 2078 & 5472 \\
\hline & & & & & \\
\hline
\end{tabular}

Cara menghitung prediksi volume parkir kendaraan sepeda motor dan mobil yaitu sebagai berikut :

Contoh 1. Prediksi Volume Parkir Sepeda Motor pada Tahun $2020(09.00-11.00)$

Diketahui :

Volume kendaraan parkir $\quad=71$ kend

Pertumbuhan Kendaraan $\quad=10,48$ kend

Penyelesaian :

Prediksi Volume Parkir $=71+((71 \times 10,48) / 100)$

$$
=78 \text { kend }
$$


Tabel 13. Prediksi Volume Mobil pada Sukaramai

\begin{tabular}{|c|c|c|c|c|c|}
\hline No & Tahun & $\begin{array}{c}\text { Volume } \\
\text { Total } \\
\text { (Kend) }\end{array}$ & No & Tahun & $\begin{array}{c}\text { Volume } \\
\text { Total } \\
\text { (Kend) }\end{array}$ \\
\hline 1 & 2019 & 138 & 31 & 2049 & 957 \\
\hline 2 & 2020 & 152 & 32 & 2050 & 985 \\
\hline 3 & 2021 & 168 & 33 & 2051 & 1014 \\
\hline 4 & 2022 & 186 & 34 & 2052 & 1047 \\
\hline 5 & 2023 & 206 & 35 & 2053 & 1084 \\
\hline 6 & 2024 & 227 & 36 & 2054 & 1124 \\
\hline 7 & 2025 & 251 & 37 & 2055 & 1169 \\
\hline 8 & 2026 & 277 & 38 & 2056 & 1218 \\
\hline 9 & 2027 & 306 & 39 & 2057 & 1273 \\
\hline 10 & 2028 & 338 & 40 & 2058 & 1308 \\
\hline 11 & 2029 & 374 & 41 & 2059 & 1313 \\
\hline 12 & 2030 & 413 & 42 & 2060 & 1318 \\
\hline 13 & 2031 & 456 & 43 & 2061 & 1325 \\
\hline 14 & 2032 & 504 & 44 & 2062 & 1332 \\
\hline 15 & 2033 & 557 & 45 & 2063 & 1339 \\
\hline 16 & 2034 & 615 & 46 & 2064 & 1348 \\
\hline 17 & 2035 & 664 & 47 & 2065 & 1357 \\
\hline 18 & 2036 & 710 & 48 & 2066 & 1367 \\
\hline 19 & 2037 & 761 & 49 & 2067 & 1379 \\
\hline 20 & 2038 & 785 & 50 & 2068 & 1391 \\
\hline 21 & 2039 & 794 & 51 & 2069 & 1405 \\
\hline 22 & 2040 & 804 & 52 & 2070 & 1420 \\
\hline 23 & 2041 & 815 & 53 & 2071 & 1437 \\
\hline 24 & 2042 & 828 & 54 & 2072 & 1456 \\
\hline 25 & 2043 & 841 & 55 & 2073 & 1476 \\
\hline 26 & 2044 & 856 & 56 & 2074 & 1499 \\
\hline 27 & 2045 & 872 & 57 & 2075 & 1524 \\
\hline 28 & 2046 & 891 & 58 & 2076 & 1552 \\
\hline 29 & 2047 & 911 & 59 & 2077 & 1583 \\
\hline 30 & 2048 & 933 & 60 & 2078 & 1617 \\
\hline
\end{tabular}

Contoh 2. Prediksi Volume Parkir Mobil pada Tahun 2020 (09.00 - 11.00) :

Diketahui

$$
\begin{array}{ll}
\text { Volume Kendaraan Parkir } & =49 \text { kend } \\
\text { Pertumbuhan Kendaraan } & =10,48 \text { kend }
\end{array}
$$

Penyelesaian :

Prediksi Volume Parkir $=49+((49 \times 10,48) / 100)$ $=54 \mathrm{kend}$

Metode parkir yang digunakan dalam penelitian ini adalah metode flat, metode progresif dan metode kombinasi, sehingga data diambil dengan cara menyebarkan kuesioner kepada pengunjung Sukaramai Trade Center. Dalam penelitian ini dalam pengambilan teknik sampel penelitian ini yaitu non probability sample melalui teknik purposive sampel [15]. Hasil dari kuesioner penelitian dapat dilihat pada Gambar 3 sampai Gambar 8.

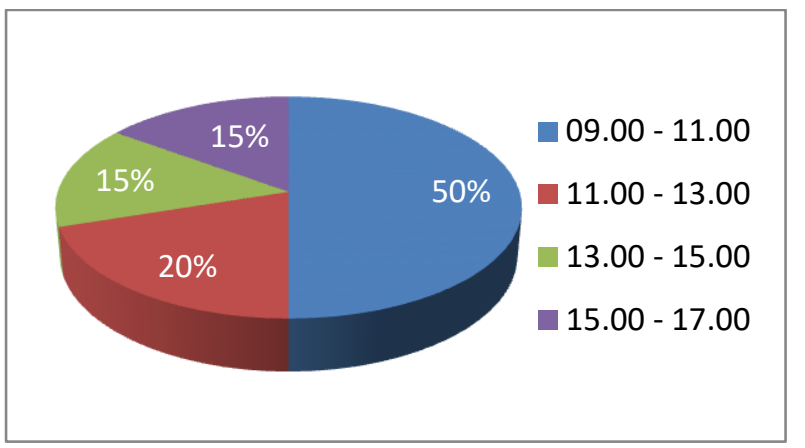

Gambar 3. Grafik Presentasi Kedatangan Pengunjung Pada Hari Senin

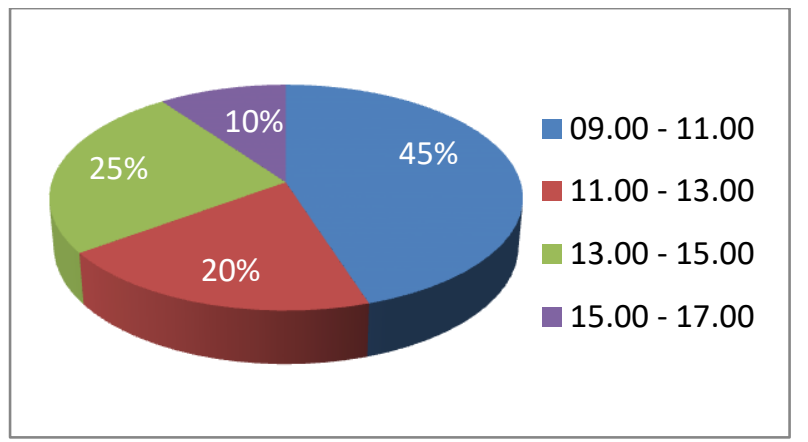

Gambar 4. Grafik Presentasi Kedatangan Pengunjung Pada Hari Selasa

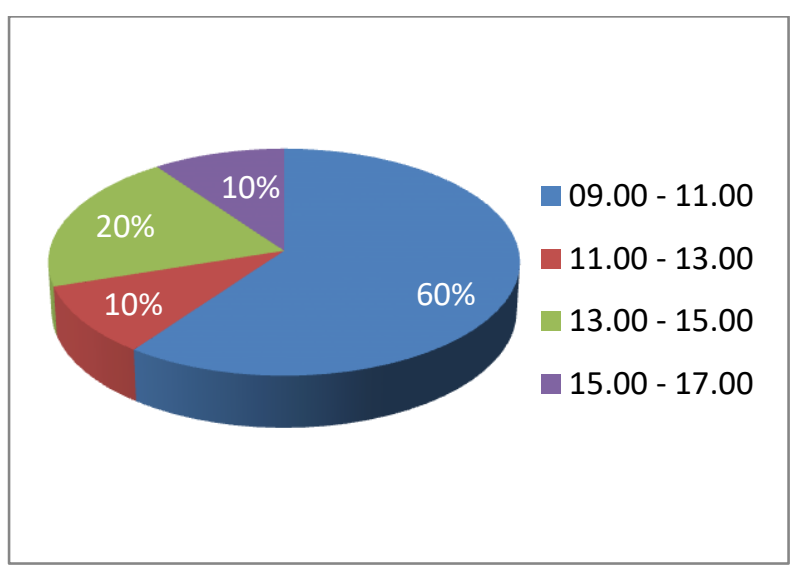

Gambar 5. Grafik Presentasi Kedatangan Pengunjung Pada Hari Kamis

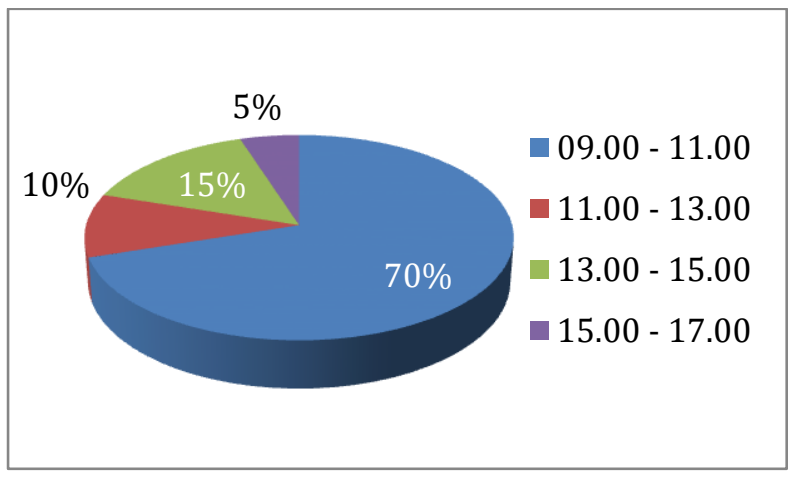

Gambar 6. Grafik Presentasi Kedatangan Pengunjung Pada Hari Sabtu 


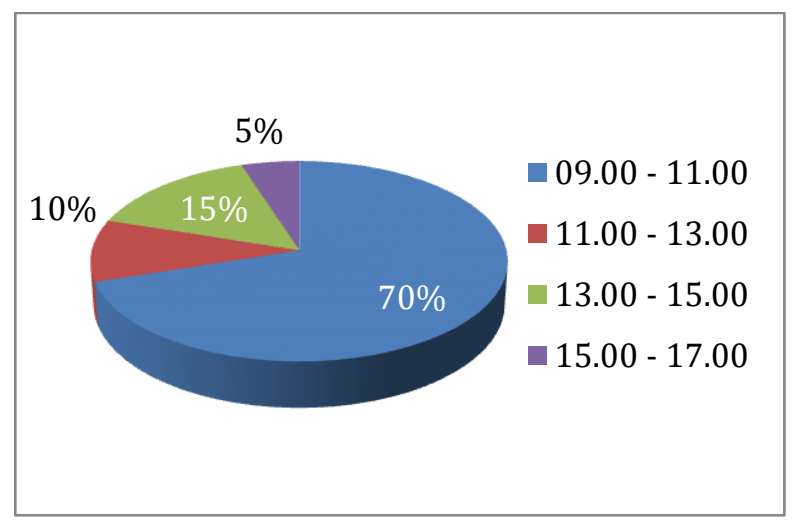

Gambar 7. Grafik Presentasi Kedatangan Pengunjung Pada Hari Minggu

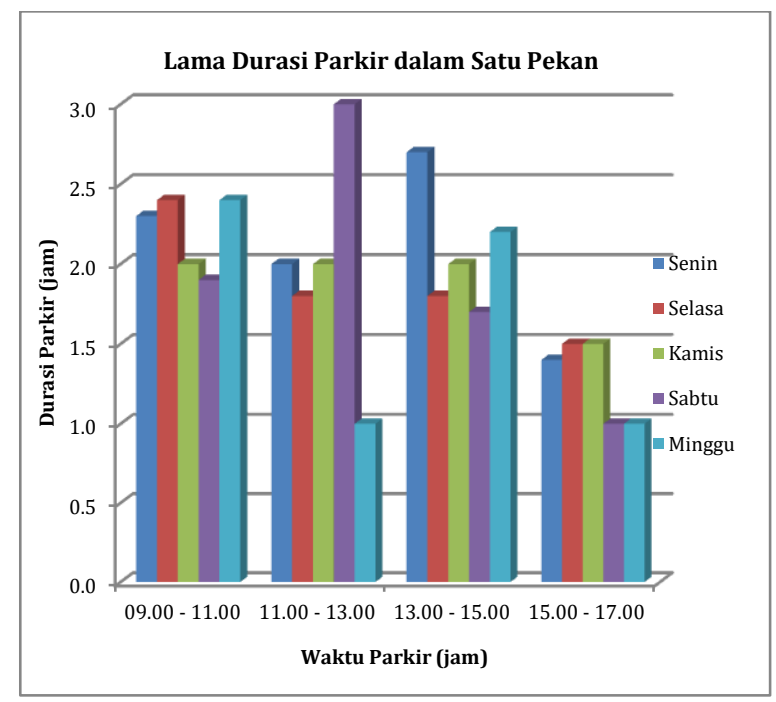

Gambar 8. Grafik Presentasi Lama Durasi Parkir Pengunjung dalam Satu Pekan

\section{Pendapatan Parkir}

Penetapan harga jasa parkir mengikuti aturan biaya parkir yang ditetapkan oleh pemerintah dan berdasarkan fasilitas parkir. Dalam merencanakan Penetapan harga fasilitas parkir untuk gedung parkir Sukaramai Trade Center II penelitian ini menggunakan pendapatan terbesar antara metode flat, metode progresif dan metode Kombinasi untuk menentukan harga parkir yang akan digunakan. secara lengkap pendapatan parkir 50 tahun dan 104 tahun dapat dilihat pada Tabel 14 dan Tabel 15.

Tabel 14. Rekap pendapatan 50 Tahun

\begin{tabular}{ccccc}
\hline & & \multicolumn{3}{c}{ Pendapatan (dalam juta) } \\
\cline { 3 - 5 } No & Kendaraan & Flat (Rp.) & $\begin{array}{c}\text { Progresif } \\
\text { (Rp.) }\end{array}$ & $\begin{array}{c}\text { Kombinasi } \\
\text { (Rp.) }\end{array}$ \\
\hline 1 & $\begin{array}{l}\text { Sepeda } \\
\text { Motor }\end{array}$ & 673.676 & 740.823 & 691.611 \\
2 & Mobil & 457.645 & 500.160 & 474.710 \\
\hline & Total & 1.131 .321 & 1.240 .983 & 1.166 .321 \\
\hline
\end{tabular}

Pendapatan (dalam juta)

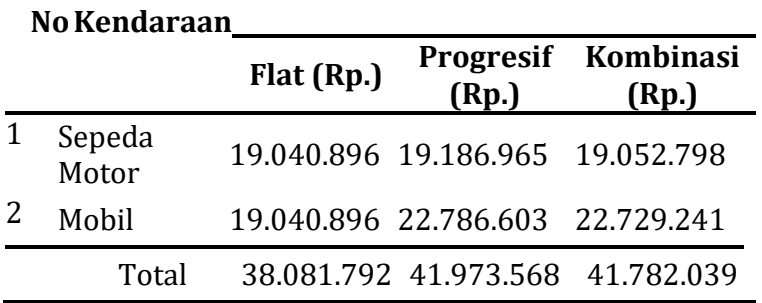

Tabel 15. Rekap pendapatan 104 Tahun

Dari tabel didapatkan pendapatan tertinggi gedung parkir Sukaramai Trade Center II dengan metode progresif baik umur 50 tahun maupun umur 104 tahun, secara grafik bisa dilihat pada Gambar 9 dan Gambar 10, Diketahui bahwa grafik pendapatan 50 tahun untuk kendaraan sepeda motor memberikan suatu gambaran bahwa grafik metode progresif lebih tinggi dari grafik metode lainnya, begitu juga dengan pendapatan 50 tahun untuk kendaraan mobil bahwa grafik metode progresif lebih tinggi sehingga untuk penelitian ini menggunakan metode progresif sebagai pendapatan untuk harga parkir digedung Sukaramai Trade Center II.

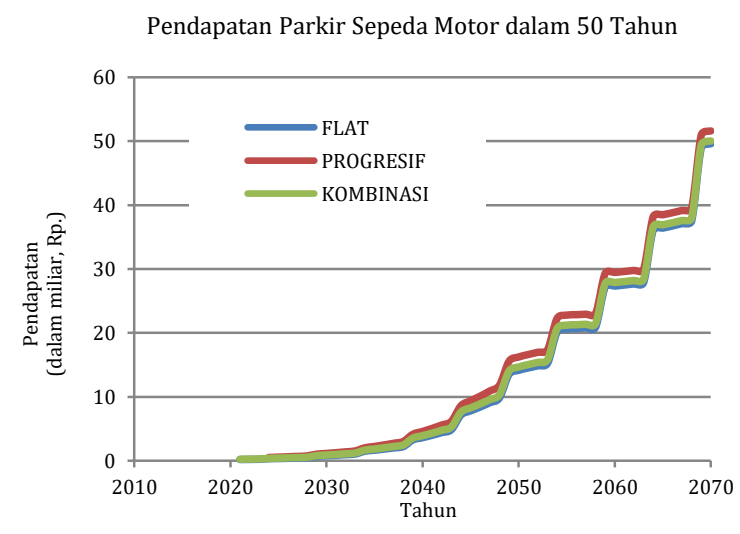

Gambar 9. Grafik Pendapatan Parkir Sepeda Motor dalam 50 Tahun

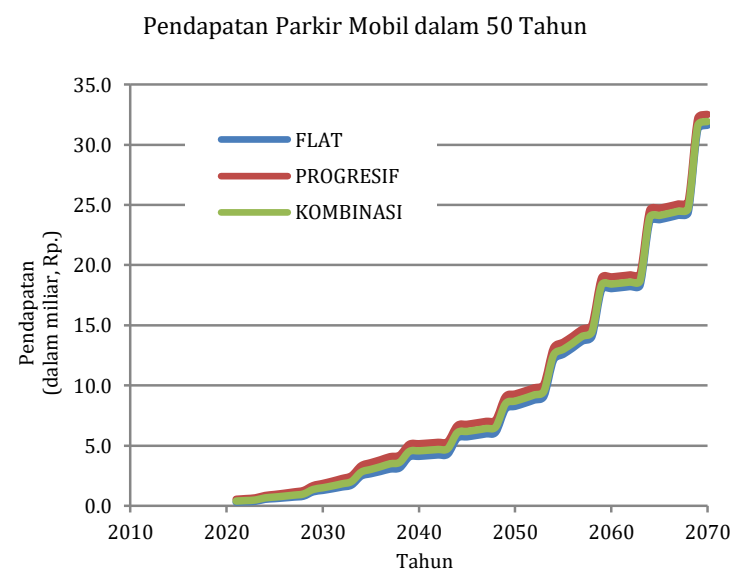

Gambar 10. Grafik Pendapatan Parkir Mobil dalam 50 Tahun. 


\section{Biaya Konstruksi dan Opersional}

Diketahui total biaya kontruksi sebesar Rp 40.425.000.000 dan Biaya Operasional, Inventaris dan Eksternal Gedung Parkir Sukaramai Trade Center II sebesar Rp 2.047.500.000, jadi jumlah modal keseluruhan adalah Rp 42.472.500.000-. sehingga biaya dalam pembangunan gedung parkir Sukaramai Trade Center II ini, terbagi menjadi biaya pembangunan (biaya konstruksi berupa biaya dari uraian pekerjaan), biaya fasilitas gedung parkir atau inventaris, biaya eksternal, dan operasional). Secara lengkap dapat dilihat pada Tabel 15 dan Tabel 16.

Tabel 15. Biaya Konstruksi Pembangunan Gedung Sukaramai Trade Center II

\begin{tabular}{|c|c|c|c|}
\hline No & Uraian Pekerjaan & $\begin{array}{c}\text { Bobot } \\
\%\end{array}$ & $\begin{array}{c}\text { Biaya } \\
\text { (dalam } \\
\text { juta, Rp.) }\end{array}$ \\
\hline 1 & Pekerjaan Persiapan & 4,64 & 1.874 \\
\hline 2 & $\begin{array}{l}\text { Pekerjaan Struktur } \\
\text { Bawah }\end{array}$ & 13,54 & 5.474 \\
\hline \multirow[t]{11}{*}{3} & Pekerjaan Struktur Atas & 81,82 & 33.076 \\
\hline & A. Lower Ground & 6,43 & 2.598 \\
\hline & B. Ground Floor & 11,14 & 4.504 \\
\hline & C. Lantai 1 & 11,21 & 4.530 \\
\hline & D. Lantai 2 & 10,28 & 4.156 \\
\hline & E. Lantai 3 & 9,71 & 3.926 \\
\hline & F. Lantai 4 & 9,65 & 3.903 \\
\hline & G. Lantai 5 & 9,77 & 3.950 \\
\hline & H. Lantai 6 & 8,02 & 3.241 \\
\hline & I. Lantai Atap & 3,00 & 1.214 \\
\hline & J. Lain-lain & 2,61 & 1.053 \\
\hline 4 & PPN 10\% & 10,00 & 4.043 \\
\hline & Total & 100,00 & 40.425 \\
\hline
\end{tabular}

Sumber : (Trimatra Liguna, 2020)

Tabel 16. Rencana Biaya Operasional, Inventaris, dan External Gedung Sukaramai Trade Center II

\begin{tabular}{clcc}
\hline No. & Keterangan & $\begin{array}{c}\text { Bobot } \\
\text { \% }\end{array}$ & $\begin{array}{c}\text { Biaya (dalam } \\
\text { juta, Rp.) }\end{array}$ \\
\hline 1 & Iventaris & 68,34 & Rp1.399 \\
2 & Operasional & 19,71 & Rp404 \\
3 & External & 11,95 & Rp245 \\
\hline & Total & 100,00 & Rp2.048 \\
\hline
\end{tabular}

Sumber : (Trimatra Liguna, 2020)

\section{Analisis Finansial}

Analisis finansial dilakukan menggunakan metode Net Present Value (NPV), Benefit Cost Ratio (BCR), dan Internal Rate of Return (IRR).

\section{Net Present Value (NPV)}

Dari hasil analisis data perhitungan nilai $\mathrm{Net}$ Present Value (NPV) pembangunan gedung STC II didapatkan nilai NPV dengan umur bangunan rencana 50 tahun sebesar -12.333.948.000, artinya nilai Net Present Value (NPV) kecil dari nol sehingga investasi dikatakan tidak layak. Setelah dilakukan analisis hingga 104 tahun, maka diperoleh nilai Net Present Value (NPV) besar dari nol yaitu 9.159, berarti investasi sudah layak.

\section{Benefit Cost Ratio(BCR)}

Berdasarkan data analisis dari hasil perhitungan Benefit Cost Ratio (BCR) dari pembangunan gedung STC II untuk masa umur rencana bangunan 50 tahun, didapatkan nilai BCR sebesar 0,504, artinya nilai BCR kecil dari 1 berarti investasi dikatakan tidak layak. sedangkan untuk umur bangunan 104 tahun diperoleh nilai BCR sebesar 0,633, artinya nilai BCR kecil dari 1 sehingga investasi juga masih belum layak.

\section{Internal Rate of Return (IRR)}

Berdasarkan analisis hasil perhitungan nilai IRR dari pembangunan gedung STC II, untuk masa umur bangunan 50 tahun nilai IRR sebesar $6,691 \%$ artinya nilai IRR kecil dari suku bunga sehingga investasi dikatakan tidak layak. Sedangkan untuk analisis umur bangunan hingga 104 tahun nilai IRR yang diperoleh sebesar 8,859 \%, berarti nilainya juga masih kecil dari suku bunga sehingga investasi dikatakan tidak layak.

Secara keseluruhan hasil analisis finansial yang didapatkan dari nilai Net Present Value (NPV), Benefit Cost Ratio (BCR) dan Internal Rate of Return (IRR) tidak memenuhi ketentuan atau persyaratan sehingga pembangunan gedung parkir Sukaramai Trade Center II tidak layak untuk dibangun. Grafik perbandingan manfaat (pendapatan) dengan biaya (pengeluaran) dapat dilihat pada Gambar 11.

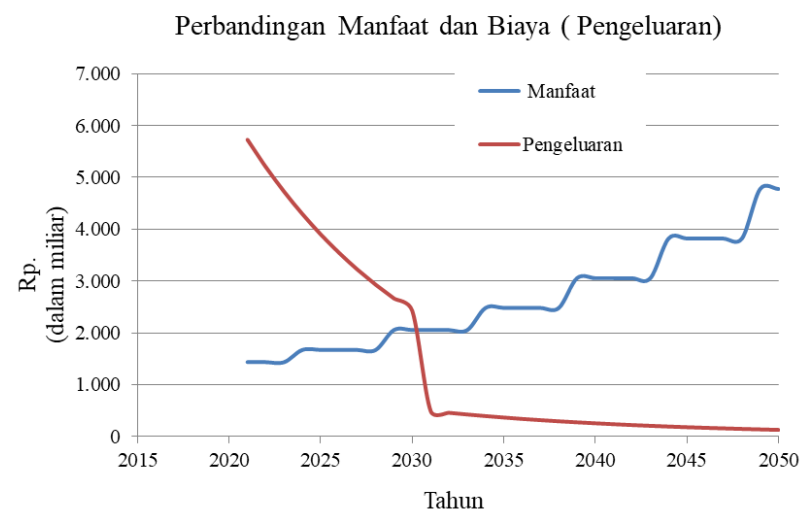

Gambar 11. Grafik perbandingan manfaat dengan biaya (pengeluaran) 50 Tahun

\section{KESIMPULAN}

Dalam menganalisis finansial dilakukan dengan metode NPV, BCR, dan IRR dengan menggunakan nilai suku bunga BUMN tertinggi yaitu Bank BTN sebesar 10,50\%. Berdasarkan perhitungan analisis finansial yang telah dilakukan pada pembangunan gedung parkir Sukaramai Trade Center II maka didapatkan hasil perhitungan 
analisis metode Nilai Net Present Value (NPV), Nilai Benefit Cost Ratio (BCR) dan Nilai Internal Rate of Return (IRR) didapatkan hasil yang tidak layak kecuali nilai NPV pada umur bangunan 104 tahun didapatkan nilai NPV positif sedangkan umur ekonomis bangunan hanya 50 tahun, sehingga pembangunan gedung parkir Sukaramai Trade Center II tidak bisa dilanjutkan dengan metode payback period dan analisis sensitivitas. Hasil dari penelitian ini tidak layak untuk dilakukan pembangunan.

\section{UCAPAN TERIMA KASIH}

Penulis berterimakasih atas dukungan dan bantuan dari pihak PT. Makmur Papan Permata serta PT. Trimatra Liguna untuk penyelesaian penelitian ini.

\section{REFERENSI}

[1] RiauPos, "Parkir di Badan Jalan Bikin Macet," Pekanbaru, p. 2, Jun. 05, 2018.

[2] T. M. Djunaedi, Achmad;Hobbs, F.D.;Suprapto, Perencanaan dan teknik lalu lintas, 2nd ed. Yogyakarta: Gadjah Mada University Press, 1995.

[3] I. G. N. KASUMA, "Analisis kelayakan finansial rencana pembangunan gedung parkir bertingkat di pasar lokitasari," 2011.

[4] J. C. Oppenlander, Manual of Traffic Engineering Studies Fourt Edition, 4th ed. Washington DC: Institute of Transportation Engineering Washington DC, 1976.

[5] M. Thamrin and R. Wiyati, "Analisis Kelayakan Penambahan Gedung Parkir Mall Pekanbaru," J. Pendidik. Ekon. dan Bisnis, vol. 6, no. 2, pp. 116-126, 2014.

[6] D. Handayani, R. Ajeng, D. Purnomoasri, and S. J. Legowo, "Analisis Kelayakan Finansial Gedung Parkir Sepeda Motor,” pp. 10221028, 2020.

[7] T. Abubakar, Iskandar; Sinaga, Elly A; Budiarso; Sinulingga, "Pedoman Perencanaan dan Pengoperasian Fasilitas Parkir." p. 204, 1998.

[8] F. E. Irawan, "Analisis kelayakan ekonomis pembangunan gedung sadewa rsud krmt wongsonegorokota semarang," pp. 311-321, 2020.

[9] M. F. Lisan, "Studi Kelayakan Finansial Pembangunan Gedung Parkir Ponpes Amanatul Ummah Desa Kembang Belor Kecamatan Pacet Mojokerto," J. Tek. Sipil
UNTAG Surabaya, vol. 8, no. 2, pp. 191-206, 2015, [Online]. Available: elisa.ugm.ac.id.

[10] M. F. Subkhan, "Analisis kelayakan finansial pembangunan rusunawa," J. Tek. sipil Prokons, vol. 8, no. 1, pp. 93-102, 2014.

[11] P. Nugraha, I. Natan, and R. Sutjipto, "Manajemen Proyek Konstruksi 1," Kartika Yudha, vol. 1, no. November 2016, p. 65, 1985.

[12] P. Yeniyati, "Kajian Finansial Pembangunan gedung Parkir Rumah Sakit Charitas," J. Berk. Tek., vol. 5, no. 1, pp. 738-753, 2015.

[13] R. P. Ariawarman, "Analisis Kelayakan Pembangunan Gedung Serbaguna Di Kota Lamongan," J. Tek. Sipil Untag Surabaya, vol. 7, no. 2, pp. 189-206, 2014.

[14] S. A. Hidayat et al., "Studi Perencanaan Gedung Parkir Terpusat Universitas Brawijaya," J. Mhs. Jur. Tek. Sipil, pp. 1-10, 2014.

[15] M. D. Rizani, "Studi Kelayakan Ekonomi dalam Pembangunan Gedung Parkir (Studi Kasus di Rumah Sakit Umum Daerah Demak)," Tatal, vol. 7, no. 1, 2011. 